\title{
SER E FAZER NA MATERNIDADE CONTEMPORÂNEA
}

\author{
BEING AND DOING IN CONTEMPORARY MOTHERHOOD
}

Tania Mara Marques GRANATO ${ }^{1}$

Tânia Maria José AIELLO-VAISBERG²

\begin{abstract}
RESUMO
O psicoterapeuta acolheu o pedido de Margarida, grávida de oito meses, de que se fizesse uso de flores em seu primeiro encontro terapêutico, como sua maneira singular de agir no mundo. Cedo percebemos que seu estilo de fazer estava profundamente marcado pelas inúmeras cirurgias e tratamentos corretivos de uma profunda fenda palatina, com a qual nascera e da qual emerge uma "guerreira", pronta para travar qualquer batalha que se the apresentasse como solução para seus problemas físicos. Paradoxalmente, ou não, Margarida "esqueceu-se" das flores, ousando fazer uma pausa em seu caminhar pelo território do fazer, para se deixar acompanhar pela psicoterapeuta, através do ser, que Ihe apontava um "defeito" intrínseco a sua natureza. O parto a apavorava e a integração entre o feminino e o masculino, o ser e o fazer, o corpo e a psique era premente. Por meio de Margarida testemunhamos a desafinação entre o ser e o fazer da mãe contemporânea.
\end{abstract}

Palavras-chave: maternidade contemporânea, gestação, clínica winnicottiana.

\begin{abstract}
Daisy's request, an light-month pregnant woman, for using flowers during her first therapeutic encounter, was received by the psychotherapist as a very singular way of realizing in the world. Soon we noticed that her doing was profoundly marked by several surgeries and clinical treatments to correct a
\end{abstract}

(1) Doutoranda em Psicologia Clínica pelo Instituto de Psicologia da Universidade de São Paulo e Coordenadora da Ser e Criar: Atendimento Psicológico à Gestante e à Mãe do Instituto de Psicologia da USP.

Correspondência com o Editor: Rua Barão do Triunfo, 550 conj. 82 Brooklin - 04602-002 São Paulo - SP - Fone/fax: (11) 5096-4159 - E-mail: tangran@mtecnetsp.com.br

(2) Professora livre-docente do Instituto de Psicologia da Universidade de São Paulo, Coordenadora do Ser e Fazer: Laboratório de Saúde Mental e Psicologia Clínica Social do Instituto de Psicologia da USP e Orientadora do trabalho de Doutorado da autora acima citada. 


\begin{abstract}
cleft lip and palate, noted after she was given birth. After this life event Daisy became a "warrior", who was always ready to fight any battle, since they were seen as a solution for her physical problem. Paradoxically, or not, Daisy has "forgotten" the flowers and dared to take a break during her way through doing domain, in order to be accompanied by the therapist through being. Delivery frightened her, because the integration between male and female elements, being and doing, body and psyche was required. We have testified, through Daisy, the lack of tuning between the mother's being and doing in the present.
\end{abstract}

Key words: contemporary motherhood, pregnancy, winnicottian clinic.

Margarida procura ajuda para a crescente ansiedade que vem experimentando desde que iniciou a licença médica, no oitavo mês de gestação de seu primeiro filho. Diz-se uma pessoa ativa, sociável e dedicada a tudo que se propõe a fazer. Costumava passar suas horas de lazer em companhia do marido e familiares ou se dedicando a uma das inúmeras atividades artesanais que domina com grande habilidade. Descobre nosso telefone ${ }^{3}$ pela internet e se interessa pelo trabalho com arranjos florais, relatando o prazer de confeccioná-los para presentear amigos e parentes, de modo que insiste em que escolhamos esta modalidade para trabalharmos. De minha parte aceito e observo que Margarida colocava, já neste primeiro contato ao telefone, duas tendências ou duas vertentes da comunicação pessoal: a verbal, expressando-se com fluência e espontaneidade sobre o que estava vivendo, e a "artesanal" da qual costumava extrair grande satisfação. Agendo nosso primeiro encontro, solicitando-lhe que trouxesse o material necessário, já que ela mostrava grandes conhecimentos na área e disposição para transformar esse fazer numa atividade terapêutica.

Margarida chega muito animada, engajando-se imediatamente numa conversação, sem trazer ou fazer qualquer referência ao material combinado. No final de nosso primeiro encontro, quando falamos de sua necessidade de estar sempre em contato com pessoas, ela faz uma pequena associação com imaginar o trabalho manual como algo a ser feito na companhia de outrem. Interessante notar como Margarida "esqueceu-se" dos arranjos florais desde esse momento e encontrou no espaço terapêutico uma oportunidade para falar de si, de forma a encontrar sentido para o que estava vivendo como sofrimento naquele momento. Além disso, o que mais a afligia é que dispositivos, antes utilizados para ocupar seu tempo e debelar a ansiedade emergente, tinham perdido sua eficácia, deixando-a em total desamparo. Não conseguia bordar, costurar, tricotar, fazer arranjos, pintar, etc. Não sentia vontade, disposição ou aquele seu já conhecido impulso para caminhar em direção às coisas que Ihe davam prazer ${ }^{4}$.

(3) "Ser e Criar": Atendimento Psicológico à Gestante e à Mãe. Serviço pertencente ao "Ser e Fazer": Laboratório de Saúde Mental e Psicologia Clinica Social do Instituto de Psicologia da Universidade de São Paulo, coordenado pela Profa. Dra. Tânia Maria José Aiello-Vaisberg.

(4) Pensamos não ser sem fundamento nossa recordação, neste ponto do relato de Margarida, sobre a distinção que Winnicott (1971b) desenvolve entre o "brincar" e a "brincadeira", situando o primeiro como fenômeno transicional (Winnicott, 1969) que tem lugar num espaço e tempo determinados e que espelha o ser, comunicando-o caso seja recebido por outra pessoa. Winnicott destaca o brincar da área da motivação instintiva, como Klein o fazia, acomodando-o no diálogo entre o eu e o mundo externo, tornando-o fazer que se alicerça no ser - situação que parece ter sido perdida por Margarida, o seu "brincar" não é mais fonte de satisfação, mas de ansiedade, porque tomado pela angústia daquele momento. Ela pede então que "brinquemos" juntas, pode até ser a brincadeira verbal da psicanálise, mas que fiquemos juntas. 
Margarida não estava se reconhecendo e solicitava um "interlocutor" nessa nova experiência, pois parecia estar perdendo a si mesma e se transformando em um outro alguém ${ }^{5}$.

Margarida é de origem interiorana e está em São Paulo há três anos. Apesar de adaptada à vida na cidade grande, nota algumas diferenças básicas: vem de uma família de sete filhos, morava numa casa grande com jardim e quintal numa cidade bem pequenina, onde todos se conheciam e ela era reconhecida pelo nome em todos os lugares que freqüentava. Estava acostumada com o movimento de sua casa, enfatizando o contínuo fazer de sua mãe, a vegetação que envolvia sua casa e o silêncio da natureza, que se contrapunham ao ruído, à poluição e ao reduzido espaço de seu apartamento em São Paulo. Estranhava também as pessoas, tendo uma certa dificuldade em confiar nelas, já que costumavam não se cumprimentar no elevador, nos corredores ou na rua. Tal atitude lhe parecia muito suspeita.

A história de Margarida foi repleta de cirurgias e tratamentos, desde os dois meses de idade, em conseqüência de uma grave fenda palatina, que a impossibilitou de sugar o seio ou a mamadeira, alimentando-se por meio de colherinhas. As cirurgias corretivas (onze ao todo) eram seguidas de tratamentos fonoaudiológicos e ortodônticos, consultas médicas e acompanhamento permanente em clínica especializada. Desse percurso não guarda como lembrança o sofrimento, a vergonha ou a desesperança; traz o holding ${ }^{6}$ (Winnicott, 1967) familiar como a marca mais profunda deixada em si, ao longo desses anos, que lhe fornecera a base para suas batalhas diárias contra 0 preconceito social e as limitações físicas que a natureza lhe impusera. Não há o menor traço de revolta no relato de Margarida, ela se transformou numa guerreira, a cada adversidade escolhia a ferramenta apropriada e seguia rumo a uma melhor qualidade de vida.

Grávida, há pouco mais de um mês da data prevista para o parto, não dispunha de armas para lidar com o vazio de sentido que se abria na experiência do novo ${ }^{7}$. Da atividade em que se lançava, costumeiramente, para a solução de seus problemas, via-se lasciva ao dormir uma tarde inteira, saboreando o "não fazer nada". Parece que o ambiente que a preparara adequadamente, durante a infância, para o excessivo uso do fazer a deixara órfã no território do ser.

Margaridalembra da ansiedade que a acompanhava no período pré-operatório, amansada pelo efeito do analgésico e pelo sono que se

\footnotetext{
(5) Margarida parecia dominar um fazer que lhe tornava familiares as intempéries da vida. Assusta-se quando tal dispositivo perde o poder confortador que tinha, esperando poder retomá-lo com a ajuda da terapeuta. Porém, cedo percebe que procurava um outro fazer, diferente daquele que dominava com as mãos. O que é fundamental ressaltar, aqui, não é o fato do fazer de Margarida ser ou não realizado manualmente, mas sua necessidade de que qualquer atividade fosse preenchida de sentido, distanciando-se da situação anterior, em que vazios de sentido eram preenchidos por atividades. Pensamos aqui estar a diferença entre passar o tempo (o passatempo) e viver o tempo (realizações).

(6) Holding é o conceito winnicottiano utilizado para a descrição do cuidado que uma mãe dispensa a seu bebê quando o envolve com seus braços, dando-Ihe sustentação tanto no sentido físico como psicológico e fornecendoIhe assim a oportunidade para que os processos inatos de integração encontrem livre expressão no sentido de organizar os elementos de self em torno de uma unidade identitária, o eu.

(7) Com "vazio de sentido" queremos nos referir à imprevisibilidade da experiência de dar à luz um filho, sentido como algo inaugural e, portanto, sem referência passada. Por mais que tentasse, Margarida não encontrava um ponto de apoio em seu passado que a retirasse do estado de alerta, pelo contrário, tudo a levava a se "armar até os dentes" e, ainda assim, sentir-se despreparada. Não há preparo para o novo, só nos resta a confiança (tema recorrente em toda a obra de Winnicott, como a situação atingida a partir de uma boa adaptação materna às necessidades do lactente) no ambiente que nos rodeia.

(8) Chamamos aqui a atenção para o fato de Margarida ter revelado, quando do primeiro contato telefônico, que não sabia ficar parada e precisava estar sempre fazendo alguma coisa. E como naquela época precisou parar de trabalhar, estava em busca de algo para fazer, já que a ansiedade se apossava dela numa situação como essa. "Não fazer nada" para Margarida era como "não existir".
} 
seguia à anestesia. Depois de cada cirurgia, a recuperação era imediata e o fazer retomado em todos aqueles detalhes que a mantinham ocupada até nova cirurgia, quando nova adaptação era requerida. Temos aqui a hipertrofia do que Winnicott (1966) chamaria de elemento masculino do self, em que sua atividade impulsiva característica, porque se realiza no contexto da vida instintiva, parecia eclipsar as expressões do elemento feminino, propiciador das experiên=cias de fusão, de indiferenciação, de deleite narcísico, que formam a base da identidade ou do sentimento de ser.

O ser não é algo etéreo, é um psiquesoma, como diria Winnicott (1949); poderíamos também chamá-lo de corpo-alma ou, ainda, de corpo habitado e é no corpo de Margarida que tantas intervenções se sucedem para corrigir algo que estava "errado". Muito se faz sobre seu ser, numa tentativa desesperada de aproximá-lo ao máximo da perfeição e, neste momento em que pouco falta para esse propósito, Margarida escolhe parar para viver a gestação e a maternidade: "ainda tem um escape do ar pelo nariz e a voz ainda não está boa, já melhorou bastante, mas agora deixa pra depois..."

Tal mudança de ponto de vista nos leva a crer no processo de Margarida rumo à preocupação materna primária ${ }^{9}$ (Winnicott, 1956) cujo desenvolvimento, de um lado, a assustava levando-a para os confins do ser e, de outro, a preparava para a tarefa materna que se baseia na adaptação sensível da mãe a seu bebê, envolvendo todo o seu ser e o seu fazer. Como mãe, Margarida precisará contar com a inteireza de si, ou seja, com elementos masculinos e femininos do eu para propiciar ao filho suas primeiras experiências de existir, de sentir-se vivo e real. Aqui é fundamental que a mãe desenvolva uma espécie de identificação com seu bebê, somente possível sobre a base do ser, para que possa imaginar o que ele precisa em um dado momento, colocando-se em seu lugar. Nesse momento de satisfação, as experiências de ser e de fazer estão entretecidas de uma tal forma, que quase não se pode distinguir uma da outra, tamanha a sintonia que nasce da intimidade entre esses dois processos.

A afinação saudável entre o ser e o fazer, entre o feminino e o masculino tem como resultado a integração do eu, a inter-relação psicossomática e a capacidade de realização no mundo (Winnicott, 1945), na qual a dicotomia eu/não-eu é resolvida pela criação de uma parceria autêntica, em que cada termo se carrega de possibilidades para o outro, sem submissão. De volta à Margarida e sua angústia, que passa então a se focalizar no momento do parto, pudemos perceber que, contrariamente as suas experiências cirúrgicas, havia um elemento que, particularmente, a preocupava: ela estaria acordada. Margarida só experimentara a rendição sob o uso dos anestésicos, reassumindo o controle da situação assim que "acordava". Porém, o que o parto requer da mulher é que abra mão do controle de si, no sentido de se deixar levar pelo processo, como quem aproveita o movimento das ondas do mar para chegar à praia, em vez de lutar contra a corrente na tentativa desesperada de se agarrar a um barco mais distante.

Margarida, paralisada pelo enigma que se impunha, não imaginava como poderia se render a algo estando acordada, ou seja, estando no controle; de outro lado, não poderia dormir, já que sua participação era aguardada em tal experiência.

\footnotetext{
(9) A preocupação materna primária é um processo no qual a mãe experimenta, nos estágios finais de sua gestação e nos primeiros meses após o parto, um estado que, do ponto de vista do observador ingênuo, se assemelha a uma doença regressiva, onde todos os seus interesses anteriores são deslocados para uma única preocupação naquele momento: seu bebê. Ela parece absurdamente absorvida por tal tarefa, chegando a preocupar seus familiares, que vêem seu comportamento como uma forma muito estranha de egoísmo e isolamento social. Com o passar do tempo, que acompanha o desenvolvimento do bebê rumo à independência, a mãe tende a "desadaptarse", retomando gradualmente sua vida anterior e deixando ao bebê a oportunidade de começar a lidar com seus relacionamentos pessoais.
} 
M-Eu não sei como vai ser, já li de tudo, já visitei o hospital, já enchi meu médico de perguntas, já sei tudo o que vai acontecer. Eu só não sei o que vai acontecer comigo!

\section{T- Como você vai se comportar...}

M-É, porque meu marido, eu não sei, ele nunca teve essa experiência, não tem criança na família dele, e se ele desmaiar? O médico já avisou que se o marido desmaia, ele fica lá no chão até acordar! Então vou ter que me preocupar com ele também? Acho melhor ele não entrar na sala de parto.

Quando a terapeuta lhe pergunta sobre a possibilidade de contar com alguém naquela situação, já que não terá o apoio das pessoas que sempre estiveram a seu lado, ela responde: "O meu médico, ali vai ser ele e eu!"

Margarida soube então que estaria acordada e só, naquele momento de sua vida, e por mais ajuda que tivesse, ninguém poderia vivê-lo em seu lugar. Se reencontrasse no fundo de seu ser o "colo" do passado, aí sim poderia se soltar, relaxar e se deixar levar, aproveitando a brecha que se abriria entre o sono e a vigília, entre o controle e o descontrole, talvez algo como um sonhar ainda que acordada. Porque o sonhar é da mesma ordem do viver (Winnicott, 1971a), e, ainda que separados no tempo, estão a enriquecer-se mutuamente, preenchendo-nos de sentido e emprestando valor à vida. Já o fantasiar paralisa, no sentido de que retira 0 indivíduo da possibilidade de agir, de ser no mundo, oferecendo como alternativa desesperada, a existência virtual, a vida onde não há vida, múltiplas ações onde não há sobre o que agir, enfim uma vida mental dissociada do psiquesoma. Pensamos que esse não é o caso de Margarida, mas ela tende a isso, à medida que "escorrega" da unidade psicossomática, conti- nuamente interrompida pela série de cirurgias e tratamentos em busca de nova unidade. Tantas reestruturações físicas podem tê-la distanciado do contínuo diálogo entre psique e corpo, entre ser e fazer, entre o sonhar e ovivere, aqui, ela buscava restaurar tal parceria. Margarida pressente que o parto inserir-se-á na fenda que separa - ao mesmo tempo que une - o sonho da vida.

Para encerrar, gostaríamos apenas de sinalizar alguns detalhes fornecidos pelo psicoterapeuta que se propõe a trabalhar com gestantes e puérperas da mesma maneira com que uma mãe se dedica ao cuidado de seu bebê. Ele não imagina que sua paciente tenha se tornado um bebê, isto seria um engano terrível, mas concebe o respeito ao movimento e ao ritmo com que se desenvolve o processo de maternidade daquela mulher em particular, como única possibilidade de crescimento emocional, tornando-se ele mesmo um facilitador. Do psicoterapeuta "sábio" (Winnicott, 1961) rumamos para o psicoterapeuta sensível às demandas de seu paciente, colocando-se mais livre para circular pelos territórios do ser e do fazer $^{10}$, permitindo-se atravessar e ser atravessado pelas vivências emocionais daquele que tem diante de si, sabendo-se coadjuvante de uma história que não lhe pertence, o autor ainda é o paciente.

Uma outra questão que, além de Margarida, tantas outras mulheres têm nos apresentado se refere ao fato de as relações interpessoais atuais, tanto quanto as profissionais, estarem tão intensamente embebidas de elemento masculino, que rouba o espaço para experiências no campo do ser, relegadas e delegadas por mulheres e homens. As mulheres de hoje demandam dos homens uma apropriação maior do elemento feminino, para que elas também possam viver o lado mais ativo ${ }^{11}$ da realização no

(10) Notar como a terapeuta se abre diante da possibilidade de fazer uso ou não do material mediador, no caso os arranjos florais, permitindo que Margarida se "espreguice" num espaço mais amplo. Aliás, ela não estava a se queixar do espaço apertado de São Paulo?

(11) Com isso não queremos dizer que o elemento masculino não possa incluir a passividade ou que o elemento feminino refira-se a uma atitude passiva, ele também é ativo. Os elementos feminino e masculino se referem a diferentes formas de estar no mundo das relações interpessoais (ativas ou passivas), remetendo-se a áreas diversas da experiência intersubjetiva: no primeiro caso estamos lidando com relações de objetos subjetivos (Winnicott, 1962) e no segundo, sujeito e objeto já se encontram em processo de diferenciação. 
mundo do trabalho. Muitas delas têm se queixado de como é difícil se restringir, ainda durante a licença-maternidade, à vida doméstica e aos cuidados de uma ou mais crianças, ansiando pelo dia em que voltarão ao trabalho, pois estão se sentindo "inúteis" ou deprimidas, enquanto cuidam de seus bebês. De outro lado, os homens parecem se equilibrar numa "corda bamba", pois já não sabem mais o que suas mulheres esperam deles: ora são exigidos na maternagem de seus filhos e esposa, ora lhes é requerida uma assertividade contundente. Temos a impressão de que a complementaridade entre o feminino e o masculino foi perdida nesses novos tempos e os dados foram novamente lançados nesse jogo de integração entre o feminino e o masculino dentro de cada um de nós. Este tem sido um jogo incômodo para homens e mulheres, pois a construção de um novo sentido estimula nossa criatividade tanto quanto nos assusta, fazendonos recuar a padrões antigos, ainda que obsoletos. Estamos testemunhando um rearranjo de elementos femininos e masculinos que, se produz confusão e sofrimento, também inaugura a possibilidade de configurações sequer imaginadas e nos conduzem a questionamentos éticos, tais como: Com quem deixo meu filho? Somente serei boa mãe se amamentar meu filho? O que importa é a quantidade ou a qualidade? Não quero trabalhar! Ou ainda: Eu preciso trabalhar! Não quero sentir dor! Homem tem que participar! Eu tenho que ficar 24 horas com ele? Não sei se serei boa mãe...

\section{REFERÊNCIAS BIBLIOGRÁFICAS}

WINNICOTT, D. W. (1945). Desenvolvimento Emocional Primitivo. In: Textos Selecionados:
Da Pediatria à Psicanálise. Rio de Janeiro, Francisco Alves, 1988.

(1949) A Mente e sua Relação com o Psique-Soma. In: Textos Selecionados: Da Pediatria à Psicanálise. Rio de Janeiro, Francisco Alves, 1988.

(1961) Varieties of Psychotherapy. In: Home is Where we Start From. New York, W.W. Norton, 1986.

(1962) A Integração do Ego no Desenvolvimento da Criança. In: O Ambiente e os Processos de Maturação. Porto Alegre, Artes Médicas, 1990.

(1966) A Criatividade e suas Origens. In: O Brincar e a Realidade. Rio de Janeiro, Imago, 1975.

(1967) O Papel de Espelho da Mãe e da Família no Desenvolvimento Infantil. In: O Brincar e a Realidade. Rio de Janeiro, Imago, 1975.

(1969) Objetos Transicionais e Fenômenos Transicionais. In: O Brincare a Realidade. Rio de Janeiro, Imago, 1975.

(1971a) Sonhar, Fantasiar e Viver: uma História Clínica que descreve uma Dissociação Primária. In: O Brincar e a Realidade. Rio de Janeiro, Imago, 1975.

(1971b) O Brincar: Uma Exposição Teórica. In: O Brincar e a Realidade. Rio de Janeiro, Imago, 1975.

Recebido para publicação em 6 de janeiro de 2003 e aceito em 18 de fevereiro de 2003. 